\section{Dental research funding available}

\section{$€ 220,000$ has been allocated in research funding by the Board} of Eklund Foundation in 2021. In May, the application portal is open for researchers within all fields of dentistry and from all parts of the world for the sixth year running.

Both experimental and clinical studies within all fields of dentistry are welcome, but projects that can be related to periodontology, implantology, or cariology will be prioritised. Researchers may apply for funding for a project in its entirety, or for part of a project.

Even though the application period runs from 1 to 31 May, the application form can be previewed at the Eklund Foundation website, eklundfoundation.org, all year round. The Board will announce the successful projects in September.

The Eklund family, owners of TePe Oral Hygiene products, created the Eklund Foundation in celebration of their longstanding relationship with the professional dental community. Since 2016, the foundation has distributed $€ 140,000-200,000$ annually, supporting odontological research worldwide - teams in Italy, France, The Netherlands, Serbia, Spain, Sweden, the UK and the USA are among the recipients. More information on previous grant recipients and their studies can be found at the website.

For more information visit http://eklundfoundation.org/.

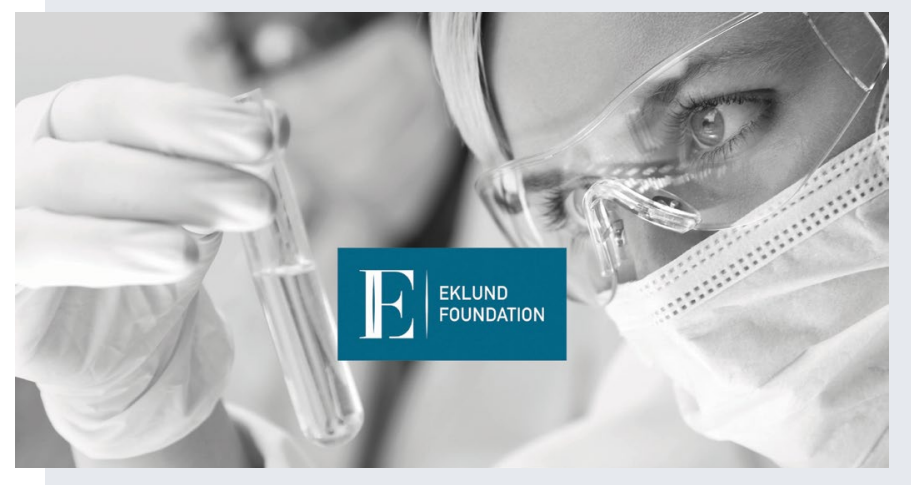

Notice of death

We regret to announce the death of Jo Eisenberg in February 2021.

\section{New BSPD safeguarding representative}

Marielle Kabban, a Consultant in Paediatric Dentistry at Guy's and St Thomas' NHS Foundation Trust, has been appointed as the British Society of Paediatric Dentistry's (BSPD's) new Safeguarding

Representative.

Dr Kabban has been a passionate advocate for child safeguarding since early in her career. She worked for ten years in the community service in South London and for a time was the dental safeguarding lead for that service.

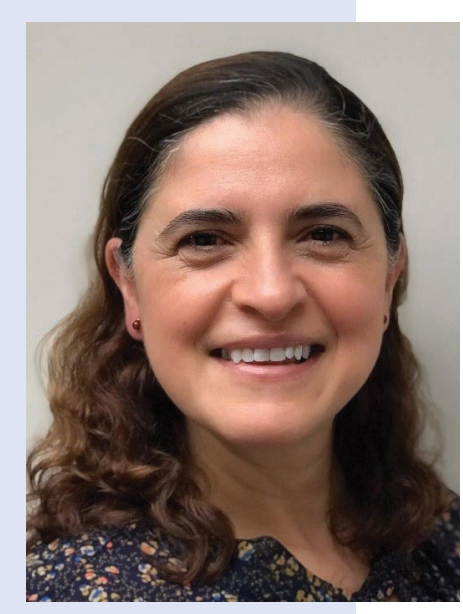

Her next role was at King's

College Hospital Dental School where she worked as a Consultant in Paediatric Dentistry, also taking on the lead safeguarding role. She recently accepted the new consultant position at Guy's and St Thomas'.

As BSPD's safeguarding representative, Dr Kabban is taking over from Jenny Harris. A member of BSPD's executive committee, Dr Harris has made it her mission to ensure that the safeguarding of children is integral to dentistry and that all members of the dental team are supported with training and resources to take on this sometimes challenging task.

It is thanks to connections Dr Harris made that the BSPD is represented at the NSPCC Health Liaison Committee and Dr Kabban takes on this responsibility as part of the BSPD safeguarding remit. She will continue as a trainer on the Child Protection Recognition and Response Course, run by the Royal College of Paediatrics and Child Health.

Dr Kabban said: 'I am excited and honoured to be taking on this role. Whilst I have big shoes to fill, [Jenny Harris] has already given me a great deal of support and remains a muchvalued mentor'.

\title{
Gum disease linked to COVID-19 complications
}

A study published in the Journal of Clinical Periodontology has found that people with advanced gum disease are much more likely to suffer complications from coronavirus, including being more likely to require a ventilator and to die from the disease. ${ }^{1}$

The research, which examined more than 500 patients, found those with severe gum disease were up to nine times more likely to die from COVID-19. It also found that patients with the disease were nearly five times more likely to need assisted ventilation.

Coronavirus has now infected around 4.1 million people in the UK. ${ }^{2}$ An estimated $90 \%$ of UK adults have some form of gum disease. ${ }^{3}$

The Oral Health Foundation is keen to highlight the importance of taking early action against the signs of gum disease, following research that suggests far too many people ignore it.
Latest figures collected by the charity show almost one-in-five Brits (19\%) immediately stop brushing the bleeding area and nearly one in ten $(8 \%)$ stop brushing altogether. ${ }^{4}$

\section{References}

1. Marouf N, Cai W, Said K N et al. Association between periodontitis and severity of COVID-19 infection: A case-control study. J Clin Periodontol 2021; https://doi.org/10.1111/ jсpe.13435.

2. UK Government. Coronavirus (COVID-19) in the UK. Daily update. Available at: https:// coronavirus.data.gov.uk/ (accessed March 2021).

3. Grant M. Nearly all of us have gum disease - so let's do something about it. University of Birmingham, 28 May 2015. Available at: https://www.birmingham.ac.uk/news/ thebirminghambrief/items/2015/05/nearly-all-of-us-have-gum-disease-28-05-15.aspx (accessed February 2021).

4. Oral Health Foundation. National Smile Month Survey 2019. UK: Atomik Research, 2019. 